\title{
Reflexão sobre o processo histórico que (des)une a língua portuguesa e a língua espanhola através dos tempos: alguns gestos de políticas linguísticas
}

\author{
Reflecting on the historical process that (un)join the \\ Portuguese and the Spanish language through the ages: \\ some signs of language policies
}

Tadinei Daniel Jacumasso*

\begin{abstract}
RESUMO: Este artigo tem por objetivo apresentar uma reflexão acerca do processo histórico que (des)une a língua portuguesa e a língua espanhola, valendo-se de alguns gestos políticos tomados pelos "gestores" dessas línguas. O referencial teórico usado para subsidiar a presente reflexão está centrado, entre outros, nos estudos de Calvet (2007), Woolard (2007) e Lagares (2013). A metodologia adotada consistiu no exame de alguns documentos e gestos político-linguísticos determinantes para 0 desenvolvimento e evolução das duas línguas analisadas. Como resultado dessa reflexão, é possível afirmar que a proximidade, digamos política, entre as duas línguas, por um lado tem sido fundamental nas tomadas de decisões acerca da preservação e expansão dessas línguas e, por outro, tal proximidade foi determinada politicamente desde a origem do português e do espanhol. A língua espanhola, amparada numa política vigorosa e silenciadora, prosperou largamente e isso fez com que a língua portuguesa, por sua vez, vivesse desde sempre e até pouco tempo atrás com uma sombra ameaçadora castelhana.
\end{abstract}

PALAVRAS-CHAVE: Política linguística. Língua espanhola. Língua portuguesa.

ABSTRACT: This article aims to present a reflection about the historical process that (un)join the Portuguese and Spanish language, taking advantage of some political actions taken by the "managers" of these languages. The theoretical framework used to support this reflection focuses, among others, the studies from Calvet (2007), Woolard (2007) and Mills (2013). The methodology consisted of examining some documents and political-linguistics signs crucial to the development and evolution of the two languages analyzed. As a result of this reflection, it is clear that proximity, like political, between this two languages, on the one hand has been instrumental in making decisions about the preservation and expansion of these languages and, secondly, this nearness was determined politically from the beginning Portuguese and Spanish. The Spanish language, supported by a strong and silencing political,

\footnotetext{
* Doutorando em Letras na Universidade de São Paulo (USP), no Programa de Pós-Graduação em Língua Espanhola e Literaturas Espanhola e Hispano-Americana. Professor assistente na Universidade Estadual do Centro-Oeste (UNICENTRO). E-mail: tadineiletras@gmail.com.
} 
prospered largely and this has made that the Portuguese language, in turn, live always and until recently with a menacing shadow Castilian.

KEYWORDS: Language Policy. Spanish language. Portuguese language.

"E é manifesto que as linguas grega e latina forão primeiro grosseiras, e os homens as puserão na perfeição que agora tem". (Fernão de Oliveira, 1988).

\section{Palavras iniciais}

Neste artigo, pretendemos refletir sobre algumas questões políticas que envolvem a língua portuguesa e a língua espanhola. A afirmação clássica de Calvet (2007) de que os homens sempre legislaram sobre as línguas é o fio condutor deste trabalho, especialmente se levarmos em conta o contido na epígrafe acima. Nesse sentido, apresentaremos alguns gestos políticos que, de certa forma, marcaram essas duas línguas ao longo da história. A escolha destes gestos apresentados neste texto e não de outros também constitui um ato de fazer política. Por entendermos que o exercício da escrita é, sobretudo, um gesto político, decidimos que neste texto os fatos históricos serão apresentados cronologicamente de modo inverso, isto é, os mais recentes serão apresentados antes e os mais antigos serão expostos depois.

Sendo assim, iniciamos nossa caminhada reversa no início do século XXI com a promulgação de duas leis: a Lei no 11.161/2005, no Brasil, e a Lei no 26.468/2009, na Argentina. A primeira ficou conhecida como a lei do espanhol e trata da obrigatoriedade da língua espanhola no sistema de ensino brasileiro. A segunda trata da inclusão da língua portuguesa no sistema de ensino argentino. $\mathrm{O}$ fato de escolhermos dois países latinoamericanos para iniciarmos a caminhada e não os dois países europeus (Espanha e Portugal) também é um gesto político-linguístico, cujo objetivo é dar lugar a uma discussão que leve em conta o fato de essas duas línguas não existirem somente na Europa. As interpretações desse gesto e de outros ficam por conta do leitor.

Há que ser destacado, logo no início desta reflexão, que não é nosso propósito apresentar um estudo comparado entre as duas línguas mencionadas. 
Isso já foi feito à exaustão ao longo da história, sendo que em cada época se adotaram métodos e perspectivas diferentes. Também merecem destaque ao leitor não familiarizado com os estudos históricos da linguística as questões de espaço e de tempo como se nos apresentam atualmente. Isso porque as fronteiras entre Portugal e Espanha, por exemplo, nunca foram tão nítidas como as conhecemos neste início de século, assim como a localização temporal não deve ser vista com a precisão que estamos acostumados a vê-la agora, ou seja, tentaremos fugir de anacronismos, contudo, se eles aparecerem, que sejam interpretados de modo a considerar as especificidades de cada período histórico ${ }^{1}$.

\section{O início da caminhada: alguns gestos político-linguísticos de reciprocidade}

Retomamos o fato emblemático mencionado anteriormente da aprovação das Leis no 11.161/2005 e no 26.468/2009. Cristofoli (2012) lembra que as referidas Leis surgiram após dois momentos que trataram de compromissos assumidos entre Brasil e Argentina em relação às línguas, os quais dizem respeito ao Convênio de Cooperação Educacional bilateral firmado entre a República Argentina e a República Federativa do Brasil, em 1997, e ao Protocolo, assinado em 2005, que prevê o ensino do espanhol e do português como segundas línguas. No Brasil, Rodrigues (2012), no seu estudo que tratou da obrigatoriedade e ensino de espanhol no arquivo jurídico e legislativo brasileiro, definiu a aprovação da lei do espanhol como um acontecimento discursivo, haja vista que é a primeira vez que se trata na legislação brasileira especificamente da oferta de uma língua estrangeira no currículo escolar. Essa lei prevê a obrigatoriedade da oferta de ensino da língua espanhola nas escolas, sendo facultativo ao aluno cursá-la ou não e deveria ter sido

\footnotetext{
${ }^{1}$ Para não sermos anacrônicos, por exemplo, devemos considerar que "[...] quando na Espanha a Constituição de 1978 chama castelhano à língua espanhola oficial do Estado, ela está nesse mesmo gesto instaurando uma política determinada a respeito das línguas de Espanha, que passam também a ser consideradas línguas espanholas" (LAGARES, 2008, p. 64). Antes desse gesto, as línguas espanholas eram o galego, o catalão, o euskera e a língua castelhana.
} 
implantada até 2010, no entanto, o Brasil "não conseguiu superar alguns problemas de organização pedagógica dos sistemas públicos de ensino" (CRISTOFOLI, 2012, p. 109) e a lei não foi implantada como deveria ter sido.

No caso da Argentina, cuja promulgação da lei é mais recente e seu prazo para implantação é até 2016, o que se percebe, de acordo com Cristofoli (2012, p. 107), é uma clareza na escrita da lei, bem como uma diferenciação quanto à obrigatoriedade de incluir em seu currículo a língua portuguesa, pois, além de ser necessário ofertá-la no ensino médio "a lei 26.468/2009 diferenciase da lei brasileira ao estender a obrigatoriedade às escolas primárias da fronteira com o Brasil (Art. $1^{\circ}$ ) e ao prever que sejam tomadas medidas para estimular a participação dos estudantes (Art. $3^{\circ}$ )". Além disso, essa lei menciona a formação docente e a necessidade de o Ministério da Educação implementar programas que deem suporte ao cumprimento da lei, o que pode fazer com que obtenha êxito, diferente do que ocorreu no Brasil.

Há que se considerar, ainda, que esses acordos e a implantação das leis supracitadas apresentam-se de diferentes maneiras para ambos os países. No Brasil, por exemplo, ensinar/aprender espanhol pode ser uma estratégia política mais enriquecedora do que fazê-lo com o português na Argentina. Isso ocorre devido à língua espanhola representar para os brasileiros um sentimento de união com os seus vizinhos e uma passagem à América do Norte e à Europa, enquanto o ensino da língua portuguesa pode ser apenas um compromisso firmado pela Argentina. Trata-se, portanto, de uma questão de política linguística mais complexa, cujos interesses comerciais, culturais e econômicos agem diretamente nas escolhas e tomadas de decisões.

Neste momento, acionamos outro gesto político: a gramática, de Antenor Nascentes, obra emblemática do início do século XX para os estudos da língua espanhola no Brasil. Nela, o autor adota uma postura positivista em relação à importância de os brasileiros aprenderem a língua espanhola. Nascentes (1920) explora, na introdução da sua gramática, o mito da I/ha Brasil, isto é, o Brasil está localizado geograficamente de modo a fazer divisa com vários países que têm a língua espanhola como língua "oficial/nacional". Segundo o autor, 


\begin{abstract}
Estando o Brasil cercado de paizes onde se fala o espanhol e com os quaes se acha em relações constantes, de ordem politica, commercial, etc., é de grande vantagem para os brasileiros o conhecimento não perfunctorio daquella lingua, assim como o da lingua portuguesa o é para os outros paizes da America do Sul. E tanto assim o comprehendeu o governo do Uruguay que creou uma cadeira de portuguez, em reciprocidade da qual a lei n. 3.674 de janeiro de 1919 creou uma cadeira de espanhol no Collegio Pedro II (NASCENTES, 1920 , p. 3).
\end{abstract}

Fica explícito, na exposição do autor, o caráter recíproco que adotam os governos brasileiro e uruguaio em relação às línguas portuguesa e espanhola. Isso é o que aconteceu, guardadas as devidas proporções, em relação à aprovação das duas leis mencionadas anteriormente. Cabe mencionar, também, que o autor não se refere a qualquer conhecimento (perfunctório) da língua do outro, mas a um conhecimento aprofundado, o qual Ihe traria vantagens. Esse discurso acerca das vantagens de se aprender espanhol no Brasil e de se aprender português nos países hispano-americanos é tema de inúmeras discussões, sendo a maioria delas vinculada a vantagens relacionadas ao mercado de trabalho, viagens etc. A exaltação de lucros em se aprender uma língua ou outra é um argumento bastante usado quando se quer fazer política linguística, ou "vender/comprar" uma língua. No caso do espanhol e do português, esse argumento se faz presente com muita frequência no início do século XXI.

Esses gestos de reciprocidade estão permeados por um sentimento de busca pela união latino-americana. Esse foi o discurso adotado nos últimos tempos, principalmente aqui no Cone Sul. Os resultados dessa política parecem não estar sendo tão satisfatórios como se projetou. Mas nem sempre foi integradora a política que tem como protagonistas as línguas portuguesa e espanhola e seus falantes. O que se nota, quando analisamos a historiografia dessas línguas, é uma disputa constante, manifestada, sobretudo no período que compreende o século XVII e o século XVIII. 
Não podemos esquecer-nos de mencionar um outro argumento que acompanha as políticas linguísticas em relação às duas línguas sob análise. Trata-se da proximidade estrutural e sonora que existe entre elas.

O espanhol é parecidíssimo com o portuguez, como toda a gente o sabe. Quem conhece o portuguez, com facilidade lê e compreende o espanhol; sentirá, é verdade, algumas deficiencias. Além disso, é uma língua familiar a nós por causa da immigração espanhola em nosso paiz, das companhias dramáticas, de operetas e zarzuelas que annualmente nos visitam, das relações com as republicas vizinhas (NASCENTES, 1920, p. 4).

A questão da imigração espanhola, mencionada por Nascentes, abre lugar para dizermos que essa ideia de aprender uma outra língua, no caso, o espanhol aprendido pelos brasileiros, para fins de tradução literária, assim como para assistir a manifestações culturais, como peças de teatro, por exemplo, permaneceu durante boa parte do século XX. Foram várias idas e vindas no que tange à inclusão e exclusão de línguas estrangeiras nos/dos currículos escolares brasileiros, sempre primando pela tradução literária. Como a educação no Brasil, de modo geral, era privilégio de poucos nessa época, por consequência, aprender línguas estrangeiras também o era. Atualmente as políticas educacionais e de ensino de línguas têm uma nova conformação, com objetivos bastante diferentes daqueles propostos no século passado.

Até agora, mencionamos dois gestos políticos acerca do português e do espanhol, um ocorrido no início do século XXI e o outro no início do século XX. Os dois possuem um caráter de reciprocidade, de modo que ilustram até aqui a união entre as duas línguas. Fazemos aqui um alerta: a publicação da gramática de Antenor Nascentes é tratada aqui e adotada como um gesto de política linguística, contudo, sabemos que na época da sua publicação não era adequado falar em política linguística no Brasil, termo surgido somente no final do século passado. Nesse sentido, alertamos que todos os outros gestos analisados daqui em diante também serão tratados como políticas linguísticas, embora saibamos que é anacrônico o seu uso. 


\title{
A caminhada continua: outros gestos de políticas linguísticas: evolução e aparelhamento das línguas
}

Voltando um pouco mais no tempo, agora no século XIX, citamos Adolpho Coelho (1868) para apresentar uma noção de evolução das línguas que se aproxima significativamente daquilo que atualmente a sociolinguística tem se ocupado em uma de suas vertentes. Nas palavras do autor, percebemos um tom de valorização à língua do povo, essa classe rude que não tem ferramentas sofisticadas, mas que faz prevalecer a sua vontade.

\begin{abstract}
As linguas produzidas no meio do cahos social hão de ser por fin bellas, cheias de vitalidade e coherencia, capazes de exprimir as mais altas especulações do espirito. É na bocca do povo, da massa rude e ignorante, que ellas se formam, e por isso trahen a cada passo as concepções ingenuas d'esse poeta sem artifício. Renegadas a principio pela classe sabia, chega porem sempre o dia do seu triunpho. Assim o latim barbaro da edade media teve que ceder o logar por toda a parte ás línguas romanas como superiores a ele (COELHO, 1868, p. 26).
\end{abstract}

Nesse ponto, trazemos um conceito-chave para o estudo das políticas linguísticas, a saber: a gestão in vivo e a gestão in vitro das situações linguísticas (CALVET, 2007). A primeira procede das práticas sociais e a outra da intervenção sobre essas práticas. Adolpho Coelho (1868) faz referência a uma espécie de gestão in vivo das línguas, ou seja, procedente das práticas linguísticas usadas pelo povo. Nesse sentido, Calvet (2007, p. 72) assinala que "de nada adianta, na realidade, prover uma língua de um alfabeto se ele não aparece na vida cotidiana dos falantes dessa língua". Com base nas palavras do autor, qualquer tentativa de legislar sobre uma língua deve levar em consideração os anseios do povo. Infelizmente, não é bem assim que as decisões sobre políticas linguísticas ocorreram/ocorrem, pois em muitos casos a "classe sábia", aquela que tem o poder, foi/é quem toma as decisões políticolinguísticas.

A noção de "melhoramento" e evolução das línguas de Adolpho Coelho remete a uma ideia de disputa entre a língua portuguesa e a língua espanhola, bastante comum no período renascentista. Na historiografia, há inúmeras ocorrências em que se tentava valorar mais uma língua que a outra, tendo 
como argumento a favor do português a aproximação ao latim, por exemplo: "melhor e mais elegante é a que mais se conforma com a latina, assy em vocábulos como na ortographia" (BARROS, 1971, p. 397) ${ }^{2}$ e a favor do espanhol o dinamismo evolutivo, por exemplo: "El castellano poseía un dinamismo que le hacía superar los grados en que detenía la evolución de otros dialectos" (LAPESA, 1988, p. 184. Grifo no original). Nesse cenário de disputa, havia/há um complicador: a distância (ou a falta dela) entre as duas línguas, como exposto por Juan de Valdés: "La [língua] portuguesa tiene más del castellano que ninguna de las otras [catalão e valenciano], tanto que la principal diferencia que a mi parecer se halla entre las dos lenguas es la pronunciación y la ortografia" (VALDÉS, 1987, p. 141). Isso implicava, na época, em que os portugueses tentassem enobrecer a sua língua, para que ela não fosse "engolida" pela língua espanhola.

\begin{abstract}
Os autores portugueses têm consciência de que tão estreita semelhança linguística representa uma ameaça para a nobilitação da língua, porquanto podia questionar-Ihe a autonomia. Não era difícil o português acabar vindo a ser tido por um dialecto do castelhano (a situação inversa: o castelhano considerado um dialecto do português, embora possível em termos linguísticos, era impensável do ponto de vista sócio-político). Assim, marcar a distinção relativamente ao castelhano significa proclamar a existência do português. São, com efeito, constantes nas primeiras gramáticas portuguesas os contrastes, do gênero: Nós portugueses dizemos.../ Eles castelhanos dizem... (CORREDOIRA, 1998, p. 51. Grifos no original).
\end{abstract}

Como se pode notar, o problema maior (se é que se pode chamá-lo de problema) deveria ser resolvido pelos portugueses. A tarefa era, ao mesmo tempo, delimitar o seu idioma e tentar afirmá-lo como língua autônoma, e não um dialeto do espanhol. Buscava-se, portanto, reconhecimento e prestígio diante dos outros. Para isso, foi necessário intensificar a codificação da língua, de modo que os instrumentos mais imediatos e eficazes se fizeram presentes: a gramática e o dicionário, nas palavras de Sylvain Auroux: a gramatização. Para Corredoira (1998),

\footnotetext{
2 Outras edições consultadas: Maria Carvalhão Buescu, Faculdade de Letras da Universidade de Lisboa, 1971; Luciana Stegagno Picchio (só o Diálogo), Módena, Società Editrice Modenense, 1959.
} 
Codificar (ou gramatizar) e elaborar significa, entre outras coisas, operar na língua escolhida uma formalização que tenda, idealmente, a torná-la unitária. É intervir culturalmente na língua, considerada, portanto, objecto sobre o que se pode e deve agir conscientemente a fim de o plasmar conforme ao modelo visado. (CORREDOIRA, 1998, p. 26. Grifos no original).

Esse gesto de codificar e elaborar a língua portuguesa se funda na tentativa de conferir sobrevivência e um certo prestígio a ela, o qual a língua espanhola já havia adquirido, principalmente porque a expansão do espanhol, de acordo com Cuesta (1988, p. 83), era tão intensa que "ameaçou fazer malograr a ainda pouco madura literatura portuguesa". Sobre o poderio espanhol, havia uma queixa portuguesa acerca da desigualdade entre os reinos, como se pode identificar nestas palavras: "somos nos com elles [...] humanos e elles connosco ingratos: porque aceytamos suas cousas com gosto, elles sofrem mal as nossa". (FERREIRA DE VASCONCELOS apud CORREDOIRA, 1998, p. 42). A esse respeito, voltando um pouco mais no tempo, é significativa a forma como Duarte Nunes de Lião (1606) naturaliza a hierarquia e o poder dos vencedores: "natural cousa he os vencedores darem leis, e língua aos vencidos", fazendo referência, no caso, à conquista romana sobre a Península Ibérica.

Nesse ponto, cabe fazer referência a mais alguns gestos políticos que são significativos do ponto de vista da gestão das línguas sob análise. A criação da RAE (Real Academia Española), em 1773, marca um momento histórico importante na difusão do espanhol e na manutenção de uma norma prescritiva para o uso da língua. Desde a sua criação, e principalmente ao longo da segunda metade do século XIX e no século XX, fundam-se, em diversos países, várias outras academias de língua espanhola, inclusive algumas com posições políticas contrárias às da RAE. Nos anos noventa do século XX, a RAE cria uma política "pan-hispânica", padronizadora da língua, com forte tendência ao anonimato ${ }^{3}$ (WOOLARD, 2007) no que se refere à língua de uma nação, mas

\footnotetext{
${ }^{3}$ A ideologia do anonimato se contrapõe à ideologia da autenticidade. Para Lagares (2013, p.
} 
com uma clara definição no que tange ao local onde deve imperar as decisões e o prestígio linguísticos: a Espanha central.

Acerca disso, Lagares (2013, p. 401) acena que "esse investimento discursivo e sua ritualização nos Congresos de la Lengua Española faz-se acompanhar de toda uma engenharia de investimento na língua como produto vendível, como recurso econômico" (LAGARES, 2013, p. 401. Grifo no original). Não são poucos os Institutos, Centros, Órgãos públicos ligados aos Ministérios de Educação, Cultura, Comércio Exterior, Associações, por exemplo, tanto na Espanha como em outros países, como a Colômbia e a Argentina, que adotam e/ou criam políticas a fim de vender idioma espanhol e uma série de outros bens ${ }^{4}$ relacionados à língua espanhola para o mundo todo.

A título de comparação, há também uma significativa diferença nos objetivos da RAE e da ABL (Academia Brasileira de Letras) 5 . O objetivo da ABL é "o cultivo da língua e da literatura nacionais". Já o principal objetivo da RAE quando foi fundada era "cultivar, y fijar la puréza y elegancia de la Léngua Castellana, desterrando todos los erróres que en sus vocablos, en sus modos de hablar, ò en su construcción há introducido la ignorancia, la vana afectación, el descuido, y la demasiada voluntad de innovar" (RAE). No sítio eletrônico da RAE há mais dois objetivos, a saber: "velar por que la lengua española, en su continua adaptación a las necesidades de los hablantes, no quiebre su esencial unidad" e "la elaboración de un diccionario de la lengua castellana, 'el más copioso que pudiera hacerse"'. De certa forma, é possível afirmar que a $A B L$, ao contrário do que faz a RAE com a língua espanhola, não cria políticas voltadas para a difusão da língua portuguesa. Bagno (2010) exalta a RAE e desqualifica

346), com base em Woolard (2007), "a ideologia do anonimato oferece fundamentos para a autoridade de línguas hegemônicas, relacionando a língua não com os falantes enquanto indivíduos concretos, mas com o 'público', de forma geral e abstrata. Para essa 'ferramenta ideológica', a autoridade reside no fato de a língua não pertencer a ninguém, ser de todas as partes e de nenhum lugar, e se fundamenta sobre a construção de uma variedade padrão que condensaria de forma neutra as características essenciais da língua". (Grifos no original).

${ }^{4}$ Por exemplo, material didático, cinema, instituições financeiras, música, turismo etc.

${ }^{5}$ Escolhemos comparar com a ABL porque, ao contrário do que ocorre com o espanhol, que tem como local central nas decisões político-linguísticas a Espanha, no caso do português os rumos da língua têm atualmente dois pólos (Brasil e Portugal). Sabemos que o mais adequado seria comparar com a Academia de Ciências de Lisboa, por exemplo. 
a ABL. Segundo o autor, "Eu não teria nada contra uma Academia de Letras se ela prestasse para alguma coisa". Na prática, a ABL contribui pouco no que diz respeito às políticas linguísticas no/do Brasil. Após a exposição desse exemplo comparativo entre as duas Academias, cabe um parêntese para dizer o quanto foi profícua a expansão da língua portuguesa pelo mundo, principalmente quando se leva em conta as precárias condições de que dispunham os seus desbravadores quando iniciaram as suas viagens saindo da Europa rumo ao "desconhecido".

Seguindo a noção de aparelhamento das línguas, trazemos para o exame - Vocabulario Portuguez e Latino (BLUTEAU, 1712), obra que inaugura o movimento de dicionarização da língua portuguesa e representa o início da consolidação da ideia do português como língua nacional ${ }^{6}$ e de cultura, criando, assim, um lugar para a língua portuguesa no mapa das línguas nacionais européias, haja vista que durante os quase dois séculos anteriores a língua espanhola reinou "quase soberana" na Península Ibérica e, nesse momento, ameaçava fazer com que a língua portuguesa fosse assimilada como uma "corrupção dialetal" do castelhano.

$\mathrm{Na}$ introdução, Bluteau (1712) anuncia que um dos principais valores da sua obra é o fato de ele, após trinta anos de trabalho, ter colocado em ordem as palavras da língua portuguesa, as quais andavam dispersas e sem hierarquia alfabética.

Tirei dos authores Portuguezes as palavras, que fora da alphabetica jerarchia andavão dispersas, \& a todas ellas, como a simulacros da eloquencia, colloquei com ordem nas aras desta Philologia; recolhi palavras antiquadas, como reliquias de Portugal o velho, \& acrescentei vozes modernas, como enfeites de Portugal o novo, entronizei nestas folhas a lingoa Portugueza com tanta magestade, que ao pé de cada dição se acha com exemplar fidelidade o Author;

\footnotetext{
${ }^{6}$ Acerca da noção de nação/nacional, entendemos ser oportuno citar Corredoira, quando afirma que: "Debalde procuraríamos antes do século XVIII o adjectivo nacional aplicado à língua. [...] Até ao século XVIII e durante boa parte dele, nação remetia com freqüência ao significado etimológico ("nascer"), como atesta, a possibilidade de permuta, sem alteração semântica perceptível, entre nação, natureza e nascimento. Mesmo quando nação referia uma comunidade étnica ou de origem (Galiza, Portugal, Aragão...), o referente era indeterminado politicamente ou, com mais exactidão, não se identificava com uma entidade política". (CORREDOIRA, 1998, p. 22).
} 
com etymologicas descendencias mostro a origem \& apuro a nobreza dos vocabulos; manifesto o parentesco, \& affinidade, que elles tem com a lingoa Hebraica, Arabica, Grega, Italiana, Castelhana, ou Franceza, \& obrigo o Latim a ter com o Portuguez primorosas coorespondencias.

Além do pioneirismo do dicionário de Bluteau, algo que merece destaque é a ampliação do léxico português. Julga-se que ele aumentou em cinco vezes o número de entradas lexicais produzido no Renascimento e no século XVII. Como diz o próprio Bluteau (1712), houve a junção das relíquias do velho português com os enfeites do novo, além de apurar a nobreza desses vocábulos. Além disso, ao passo que entendemos esse esforço de Bluteau como um gesto político-linguístico de extrema relevância para instrumentalizar a língua portuguesa, nossa análise se centra no fato de ele ter marcado na sua obra os limites entre o português e o espanhol, quando diz: "manifesto o parentesco, \& affinidade, que elles [os vocábulos] tem com a lingoa Hebraica, Arabica, Grega, Italiana, Castelhana, ou Franceza", ou seja, trata de um parentesco com a língua espanhola, de modo que cita antes outras quatro línguas para depois citar essa. Na mesma toada, Bluteau não deixa de fazer referência às primorosas correspondências que o português deve ter com o latim, a língua mãe.

\section{A nossa caminhada se aproxima do fim: para isso, nada melhor que um clássico}

Para concluir o exame de documentos que consideramos aqui como singulares no que se refere a gestos político-linguísticos, trazemos para análise um clássico: Duarte Nunes de Lião (1606). Na citação a seguir, há uma mostra da relação estreita que (des)unem a língua espanhola e a língua portuguesa.

Era a língua Portuguesa na saída daquele cativeiro dos Mouros mui rude, e mui curta, \& falta de palavras, e cousas, por o mísero estado, em que a terra estivera: o que lhe conveio tomar de outras gentes, como fez. Polo que sua meninice foi no tempo del Rei dom Afonso VI, de Castela, e no do Conde dom Henrique até o del Rei dom Dinis de Portugal que teve alguma policia, e foi o primeiro que pos as leis em ordem, e mandou fazer compilação delas, e compôs muitas cousas em metro à imitação dos Poetas Provençais, como se melhorou a 
língua Castelhana em tempo del Rei dom Afonso o sábio seu avô, que mandou escrever a crônica geral de Espanha, e compilar as sete partidas das leis de Castela, obra grave, e mui honrada, posto que rude nas palavras, como também mandou trasladar muitos autores da língua latina na Castelhana.

E assi se foram ornando ambas as línguas, Portuguesa e Castelhana até a policia em que agora estão. (LIÃO, 1606, p.30-33)

A partir desse fragmento, podemos fazer alguns destaques que nos parecem fundamentais do ponto de vista da perspectiva que adotamos, isto é, da relação entre a língua portuguesa e a língua espanhola. O primeiro deles é a noção de ornamento das línguas, mostrando, assim, naquela época uma noção de evolução das línguas e de "policia em que agora estão". Essa noção pode ser contraposta ou geradora à/de uma noção sociolinguística de que as línguas mudam com o passar do tempo: variação ou mudança diacrônica. Também está presente em Duarte Nunes de Lião a comparação entre o que foi feito em cada língua para que elas alcançassem o estado em que se encontravam naquele momento, fazendo referência explícita aos gestos políticos de melhoramento que fizeram os reis de Portugal e Espanha. O autor apresenta também um gesto importante na manutenção e difusão de uma língua: a tradução. No caso, ele cita as traduções de obras do latim para o espanhol. Além disso, merece destaque a forma como o autor se refere à sabedoria do reino espanhol, que mandou escrever a crônica geral de Espanha.

Ademais, cabe fazer referência à noção de oficina da língua exposta por Duarte Nunes de Lião (1606).

Da qual língua galega a portuguesa se avantajou tanto, quanto na cópia como na elegância dela vemos. O que se causou por em Portugal haver reis e corte, que é a oficina onde os vocábulos se forjam e pulem e donde manam para os outros homens, o que nunca houve em Galiza.

Esse trabalho de "polimento" da língua, conforme assinala o autor, é um gesto característico de políticas linguísticas, haja vista que faz menção ao fato de haver naquela época, em Portugal, reis e corte, ou seja, havia uma centralidade naquilo que se determinava em relação à língua, algo parecido com o que ocorre na nossa modernidade, quando os governos criam leis para a 
integração regional da América do Sul, por exemplo, tratado no início desta exposição. Em havendo reis e corte, a língua poderia ser forjada, polida e difundida para outros lugares e outras gentes. Fazendo alusão, dessa forma, ao clássico de Max Weinreich (apud ROSA, 2000, p. 23) "uma língua é um dialeto com exército, marinha [e aeronáutica]"

O caso do galego merece um destaque especial para finalizar esta reflexão, haja vista que pela falta de um reino, conforme diz Duarte Nunes de Lião, na formação dos estados espanhol e português, o galego foi tido "ideológica e politicamente" como um dialeto. Bagno (2011), um dos defensores de que português não procede do latim, mas do galego, assinala que pela fala de um Estado soberano, o galego "sempre viveu no inferno do não-ser". Segundo o autor,

A Galiza passou a formar parte da coroa de Castela e Leão em 1230 e a partir daí foi perdendo a sua autonomia política a favor de Castela. Esse quadro político apresenta, de um lado, a Galiza: um território sem governo próprio durante 750 anos, uma região que é em tudo tributária e dependente de um Estado central espanhol, marcado, ao longo de sua história, por uma forte política de silenciamento das identidades étnicas subestatais de esmagamento das lutas em favor da autonomia dos povos submetidos à sua coroa e de substituição planejada das línguas locais pela língua oficial, castelhana, que deixa de ser um dialeto local, o dialeto de Castela, para receber o título nobiliárquico de "língua espanhola". Do outro lado, literalmente do outro lado do Rio Minho, fronteira natural que sempre demarcou os dois territórios, está Portugal: país independente, reino autônomo desde o século XII, Estado soberano, inimigo secular de Castela, sempre muito cioso de preservar sua liberdade política diante da vizinha Espanha, mais poderosa e maior. [...] Com isso, temos uma língua: o português, língua de um Estado soberano, e temos o galego, que sempre viveu no inferno do não-ser, porque the falta precisamente um Estado soberano (BAGNO, 2011, p. 36).

Fica claro na exposição do autor aquilo que tentamos mostrar ao longo desta reflexão. A proximidade, digamos política, entre as duas línguas, português e espanhol, por um lado tem sido determinante nas tomadas de decisões acerca da preservação e expansão dessas línguas e, por outro, essa proximidade foi determinada politicamente desde a origem delas. A língua

\footnotetext{
${ }^{7}$ A frase original é: "a shprakh iz a diyalekt mit an armey un a flot" ("uma língua é um dialeto com exército e marinha").
} 
espanhola, amparada numa política vigorosa e silenciadora, prosperou largamente e isso fez com que a língua portuguesa vivesse desde sempre e até pouco tempo atrás com uma sombra ameaçadora castelhana. Vale citar como exemplo, para arrematar a reflexão, que, de meados do século XV até fins do XVII, a corte portuguesa era bilíngue, sendo o espanhol a língua conferida de prestígio. Sobre isso, Corredoira (1998, p. 43) exemplifica dizendo que "os homens de letras portugueses continuam a produzir em castelhano até começado o século XVIII, quando começa a ser substituído pelo francês". Ou seja, a história das duas línguas que examinamos resumidamente está permeada de exemplos e gestos políticos que as (des)une.

\section{Referências}

ARGENTINA. Ley 26.468, de janeiro de 2009. Establécese que todas las escuelas secundarias del sistema educativo nacional, incluirán en forma obligatoria una propuesta curricular para la enseñanza del idioma portugués como lengua extranjera, en cumplimiento de la Ley $\mathrm{N}^{\circ} 25.181$. Disponível em: <http://files.aapp.webnode.com/200000065-572bb5825c/Ley_26468.pdf >. Acesso em 14 jan. 2015.

BAGNO, Marcos. Academia de letras pra quê?, 2010. Disponível em: <http://www.portuguesegramatica.com.br/media/bagno/27-academia deletraspraque.pdf >. Acesso em 18 maio 2014.

BAGNO, Marcos. O português não procede do latim. Uma proposta de classificação das línguas derivadas do galego. À busca do tesouro, n. 191, 2011, p. 34-39. Disponível em: <http://www.editorialgalaxia.es/ imxd/libros/doc/1320761642191_Marcos_Bagno.pdf> Acesso em: 18 jan. 2015.

BARROS, João de. Gramática da língua portuguesa, seguida de Diálogo em Louvor da nossa linguagem, Lisboa. Faculdade de Letras da Universidade de Lisboa, 1971.

BLUTEAU, Raphael. Vocabulario portuguez e latino: aulico, anatomico, architectonico... Coimbra: Collegio das Artes da Companhia de Jesus, 1712.

BRASIL. Lei No 11.161, de 5 de agosto de 2005. Dispõe sobre o ensino da língua espanhola. Disponível em: <http://www.planalto.gov.br/ccivil_03/ _ato2004-2006/2005/lei/L11161impressao.htm> Acesso em 12 jan. 2015. 
CALVET, Lois-Jean. As políticas linguísticas. Tradução Isabel de Oliveira Duarte, Jonas Tenfen, Marcos Bagno. São Paulo: Parábola Editorial: IPOL, 2007.

COELHO, Adolpho F. A lingua portugueza: phonologia, etymologia, morphologia e syntaxe. Coimbra: Imprensa da universidade, 1868.

CORREDOIRA, Fernando Vázquez. A construção da língua portuguesa frente ao castelhano: o galego como exemplo a contrário. Santiago de Compostela:

Edicións Laiovento, 1998.

CRISTOFOLI, Maria Silvia. Políticas para a educação básica: as línguas estrangeiras nos documentos do MERCOSUL educacional e legislação do Brasil e da Argentina. In: CORIA, Adela; REGUERA, Alejandra (Org.). $V$ ENCUENTRO INTERNACIONAL DE INVESTIGADORES DE POLÍTICAS EDUCATIVAS, 5., 2012, Córdoba. Resumos... Córdoba, 2012. p. 103-111.

CUESTA, Pilar Vásquez. A língua e a cultura portuguesas no tempo dos Filipes. Sintra: Publicações Europa-América 1988. $1^{\text {a }}$ ed. orig. esp. 1986.

LAGARES, Xoán Carlos. O galego e os limites imprecisos do espaço lusófono. In: MOITA LOPES, Luiz Paulo da (Org.). O português no século XXI: cenário geopolítico e sociolinguístico. São Paulo: Parábola Editorial, 2013. p. 339-360.

LAGARES, Xoán Carlos. Sobre a noção de galego-português. Cadernos de Letras da UFF. Dossiê: Patrimônio cultural e latinidade, Niterói, n. 35, p. 61-82, 2008.

LAPESA, R. Historia de la lengua española. Madrid: Gredos, 1988.

LIÃO, Duarte Nunes de. Origem da lingoa portvgvesa. Biblioteca Nacional de Lisboa, 1606. Disponível em: <http://purl.pt/50> Acesso em 12 jan. 2015.

NASCENTES, Antenor. Grammática da lingua espanhola para uso dos brasileiros. Rio de Janeiro: Livr. Drummond Editora, 1920.

OLIVEIRA, Fernão de. Grammatica da lingoagem portuguesa. Edição facsimilada. Lisboa: imprensa Nacional-Casa da Moeda, 1988. Original 1536.

RODRIGUES, Fernanda Castelano. Língua viva, letra morta: obrigatoriedade e ensino de espanhol no arquivo jurídico e legislativo brasileiro. São Paulo: Humanitas, 2012.

ROSA, Maria Carlota. Introdução à morfologia. São Paulo: Contexto, 2000. VALDÉS, Juan de. Diálogo de la lengua. Madrid: Cátedra, 1987. Original 1737.

WOOLARD, Kathryn A. La autoridad linguística del español y las ideologias de la autenticidad y del anonimato. In: VALLE, José del (Ed.). La lengua, ¿patria común? deas e ideologías del español. Madri: Iberoamericana, 2007. p. 129-142. 